\title{
THE CZIMBALOM, HUNGARY'S NATIONAL INSTRUMENT
}

\author{
By ARTHUR HARTMANN
}

$I^{x}$

$T$ is to ancient Asia that we have to look for the origin of the Crimbalom! On tablets taken from the ruins of Nimrud now in the possession of the British Museum, we find the progenitor of this instrument documented. The fall of Nimrud, preceding that of Nineveh ( 625 B. C.) as it did by several centuries, preserved for us these relics, and again in the ruins of Nineveh, more relics have been found which establish, beyond all question of doubt, the forefather of our modern Crimbalom.

The original name of this musical instrument is lost to history, the nearest known being the Asor. This, however, was not a purely Assyrian, but a Hebrew instrument, meaning (as its name Asor implies) "Ten-stringer." While the Assyrian instrument was different from the Hebrew Asor we give it here, because it seems to have been the one nearest related to the Assyrian instrument. Formerly this instrument was regarded as one independently developed, different from the Hebrew Nebel; the more recent critics of the Bible see in the Asor only an abbreviation of Nebel-Asor, i. e. ten-stringed Nebel, in contradistinction to Nebels with a still more varied number of strings.

The Asor of the Hebrews was therefore a species of Nebel, of an oblong square or triangular shape, mounted with ten strings, which were struck or twanged by means of a plectrum.

Unfortunately, the information transmitted to us about the Asor, is like most other information regarding the Hebrews too meagre: it does not convey an exact idea of the instrument's construction, for, while Asor means "Ten-string," there were Asors of nine and eight. Furthermore, the Asor is delineated on a brick obtained from the ruins of Nimrud, (to repeat, several centuries prior to the destruction of Nineveh) and now in the British Museum, which shows an instrument of six strings.

It was strung horieontally, one string above the othor, at regular distances, the lowest string being the shortest, hence producing the highest tone and the uppermost, the longest, pro- 


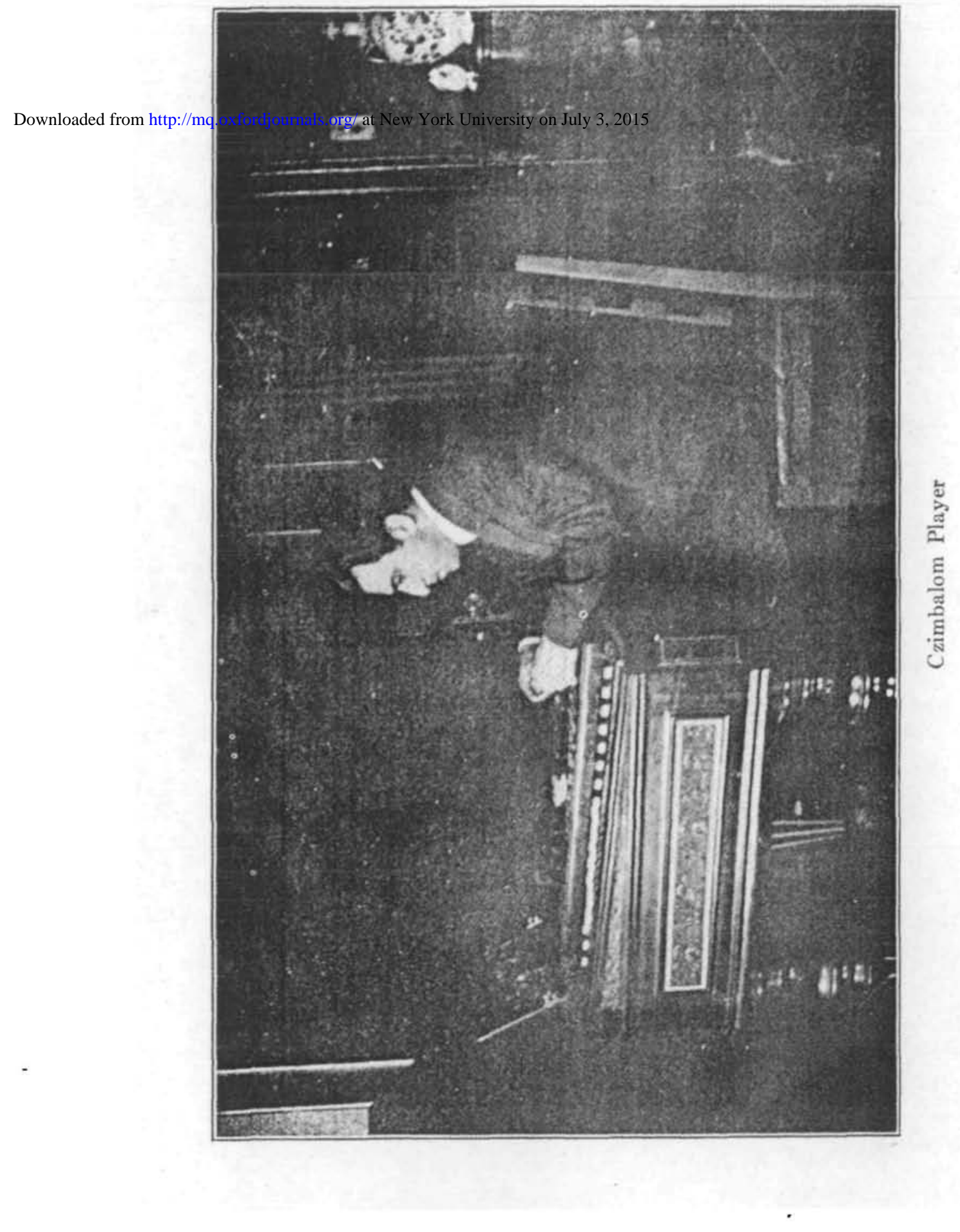




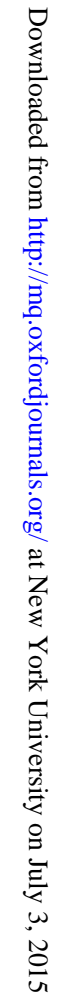


The Crimbalom, Hungary's National Instrument 591

ducing the deepest tone. The free ends of the strings hung down, probably as an ornament.

The player fastened the instrument to his body or supported it by a belt passed around his shoulder and struck the strings with a long plectrum held in his right hand. This plectrum was probably made of wood or ivory and was not held at one end as usual, but in the middle. The left hand was used to check the vibrations.

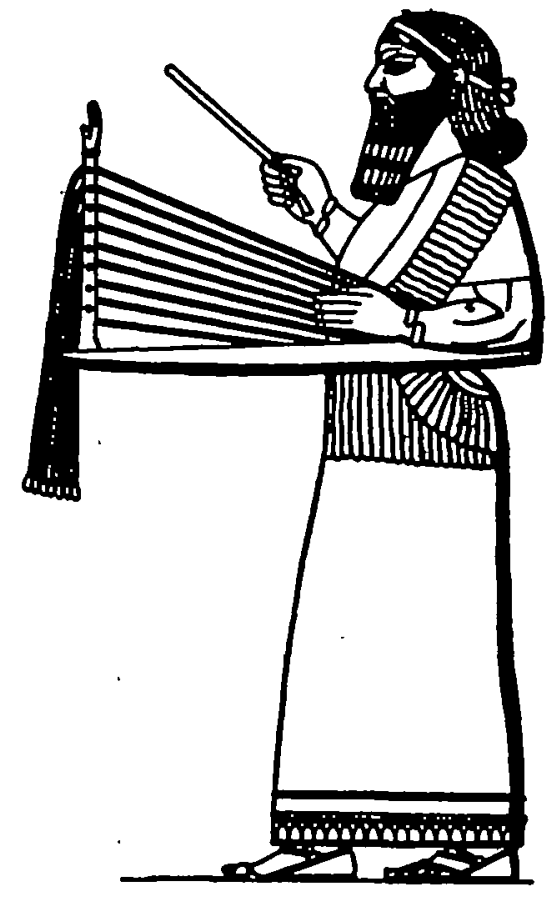

Assyrian Asor

The Asor seems to have been a favorite instrument with the Assyrians or at least with the higher classes, since it is introduced more frequently in their sculpture than any other, and generally at the entertainments and sacred rites of the monarchs. It never appears in combination with other stringed or wind instruments and never singly, but always at least two together. Perhaps they were tuned differently for the sake of fuller harmony. As the number of the tuning pegs is seldom in accordance with that of the strings, no great reliance can be placed on the representation of the strings or tassels. 


\section{Another Progentror or the Cemaralon.}

It is this time in China that another primitive form of the Hungarian instrument looms on the horizon. Its name is the Knv (or Ch'in) or Scholar's Lute.

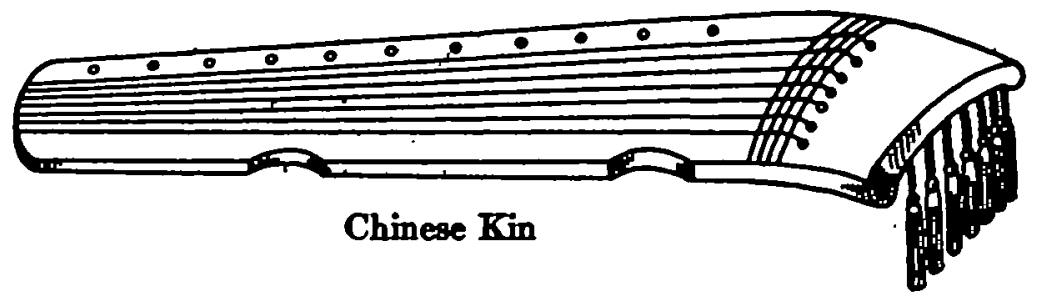

Kin in its broader sense means in Chinese the plural or majority of string instruments, and in its narrower refers to a tradition to be traced to Fo Hsi. In reality, however, it is the type of the ideochordic bamboo, forming the Valihe family and dating to a prioric psalterium.

The original number of its sille strings was five, symbolical to the Chinese of the five elements. The body of the instrument (made of lacquered rood and four feet long and eight inches wide) consisted of a narrow, curved hollow, (symbolical of the Heavens), a flat top, (symbol of the Earth), and the strings already alluded to. These were soon augmented to the number of seven, which near the broader end of the instrument passed over a bridge and through holes in the body of the Kin were fastened on the bottom side of the instrument. These strings wiere plucked-twanged without the use of a plectrum. Their tone is very soft.

The Ch'in is used for what is called elegant music. It is supposed to be the special instrument of the educated classes; yet it is somewhat neglected by the present generation, and is scarcely met with except at imperial ceremonies. This may be attributed to the fact that the playing on the $\mathrm{Ch}^{\prime}$ in is surrounded with difficulties enough to deter the most willing learners. The notation, for instance, is peculiar: each note being a compound of several simple characters, so arranged as to convey at once to the eye of the performer the note to be played, the string to be chosen, the finger to be used, etc. Ultimately more strings were added, so that there have been Kins of twenty-five and even more strings.

It is claimed that formerly the instrument was tuned

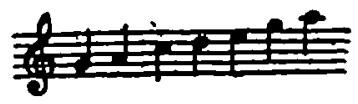


The Crimbalom, Hungary's National Instrument 693

which has been modified to the present-day

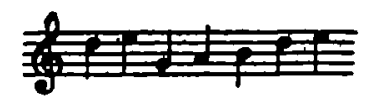

However, we incline more to the belief that its tuning is the following:

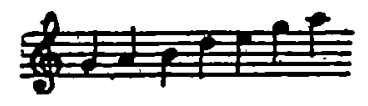

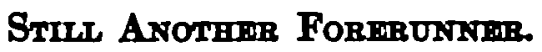

Again in Asia, this time among the Arabs, we encounter the third variation of our Cximbalom in the so-called KANON, a favorite instrument among the ladies of the wealthy classes of Turkey.

The body is of light wood, beautifully marked, and it is strung with seventy-two strings of gut, in sets of three, producing twenty-four distinct tones. It is played with a small plectrum of tortoise-shell or silver.

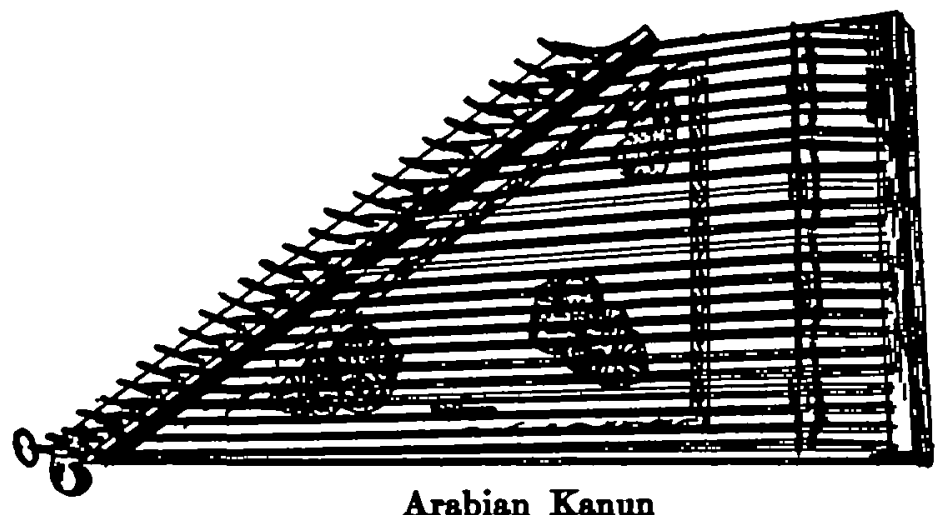

In the middle ages, the Kanun found its way into Europe. Evidences of this are to be seen in Orcagna's wall frescoes, "Trionfo della Morte" in the Campo Santo of Pisa; depicting a lady vocalist, accompanied by the Kanun (or Kanoon), entertaining an assembly.

\section{The Dulctmer.}

The origin of this instrument is unknown' Its length is thirty inches, width fourteen inches, and it is strung with twenty-six sets of three-wire strings each. 
The Santrir.

It is unquestionably this Arabian instrument-greatly appreciated in Turkey, too-which embodied the principles on which the modorn Crimbalom was perfected.

It has eighteen sets of wire strings, each set consisting of four strings tuned in unison. In the middle are two rows of movable bridges, by means of which the pitch is regulated. It is played with two little wooden hammers. Length two feet eight inches; width eleven and one half inches.

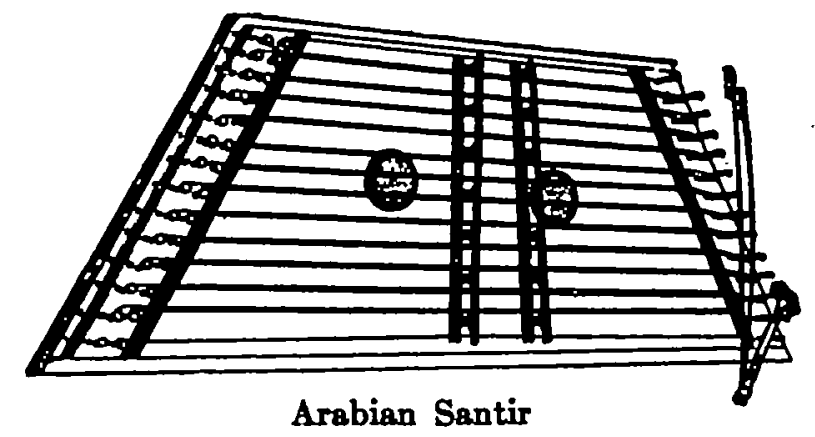

Thy Panuterium.

In a lesser degree, the pattern of the Czimbalom exists also in the Psalterium, that three-cornered small harp, much used in the middle ages by various nations.

In no way should one confound the Crimbalom with the very similar Cymbalum, the plate-shaped brass instrument of the Greeks and Romans which was also employed by the ancient Egyptians and Hebrews.

The primitioe form of the Crimbalom was brought into Europe by the Nomads, the wandering hordes of Asia. With the Arabian invasion of Spain in the eighth century after Christ, they introduced their musical instruments, the Kanun among others, into Europe. Gradually, the touch of evolution reached in its refining path the Kanun as also the Santir, and thus we find that at different times, different peoples re-baptised these instruments according to their individual likes.

The Germans called it the Hackbrett, the French, tympanon, the English, dulcimer, while the Italians alternated between saltiero tedesco and combalo, though they-it should be notedalso called the harpsichord "cembalo." We also find that with the introduction and development of the Crimbalom in Europe, 
the learned theorists of the sixteenth century, Virdung and Agricala, and a century later Praetorius, became interested themselves in the instrument with its flat and trapeze-like box of steel strings which by that time had come to be struck with two little hammers.

This style of instrument, the Hackbrett, etc., enjoyed considerable vogue for a long time, and is still to be found in the Appenzell', among the Austrian mountain population as also, ocasionally, among the Hungarian mountaineers.

The fifteenth and sixteenth centuries show a departure in the strings of the Hackbrett; the ends are now ro-inforced with small brass tongues and the tone itself is produced by contact with a hard hammer. The pressure on the keys raised little brass tongues which reached the strings, like hammers on the modern piano. This instrument was called the Clavichord. If at the edge of the hammer the quill end of bird's feathers touched the strings, the instrument was called the Clavicymbal or Clavicombalo. The end of the eighteenth century saw both these instruments superseded by the modern hammer piano.

The primitive forms of the Cximbalom are documented not only in numerous paintings, (for instance, in Tintoretto's "Paradise" where alongside of David's harp a Czimbalom is seen) but in numerous specimens preserved: in the South Kensington Museum of London, under the inscription of "salterio tedesco" are eight omall Crimbaloms, their frames artistically laid out in mosaics of variegated design. These instruments, of Italian manufacture, are several hundred years old. In the antique room of the Luxembourg (Paris), a beautiful small, gilt Crimbalom of the epoch of Louis XIV attracts our attention. Its little white lid is covered with exquisite paintings. At the Paris Exposition of 1878 at the Trocadero, three old Crimbaloms aroused much comment and admiration. One, having but twenty-one strings, dating from the XVII century, was sent from Brussels. The second was listed as a "Psalterion" and the third, an instrument with twenty-three strings and decorated in oil, with figures of musicians playing, was registered as a "Tympanon." Dr. Julius Schaarschmidt writing in the "Budapesti-Hirlap" in 1885, drew attention to a Chinese Czimbalom which was exhibited in the Ethnographical museum of Munich in the Chinese-Japanese division; as also to a XVII century Hackbrett which had found its way from the Appenzell and which the Munster of Basel

1Appensell (trom Abbatis Celle), a canton in the north-ast of Switserland. Area 168 square miles divided into two districts. 
claimed to have found in the relics of the middle ages. The frame of this Hackbrett is of unpainted wood and its wire strings have the same division which the treasured Chinese instrument in Munich has. The knockers, however, are not padded at their ends with cotton.

\section{The Czmoaloy no Hungary.}

Though it is not altogether impossible that the Hungarians did not bring the Crimbalom with them from their original home in the Ural-Asiatic regions, it would be very difficult to prove it.

Every indication seems to point to the probability that the Crimbalom was at home in Hungary considerably before the gypsies. As the instrument was known in Europe several hundred years before the epoch of Nagy Lajos and King Zsigmond (the time when the gypsies settled in Hungary) it is but natural that the Hungarians should have become acquainted with it quite early in its first passage of the gates of Europel.

In the list of instruments enumerated by Anonymous of the XII century (King Bela the Third's secretary) the Crimbalom is cited among the harp-like and zither-like instruments. That at the meeting of the magnates in 1525, the gypsies not only performed on this instrument but that it had firmly established a home in Hungary, of this we have ample proof.

In the diary of Tamas Villimen, Venetian Ambassador to the Court of Matyas the first, at Ofen (Buda) -end of the XV century -we find enthusiastic mention of a certain Márton, the Court musician, "who with consummate mastery and great love plays on that peculiar instrument which I have found only among the Hungarians and which they call the Crimbalom."

At the crowning of Matyas $I$ (King Mathew the second) history records that a nine-year old child performed on the Crimbalom, and in the times of Rakbcri, the Crimbalom was distributed all over Hungary, both as a solo instrument and in the orchesrras (sypsy bands.)

Komjatti Benedek who translated the Bible in 1533, knew well the voice of the Crimbalom and in Albert Molnar's dictionary, which appeared in 1621, the Crimbalom is listed. On the other hand, it is quite amazing that the Szatmárs' poet, Bod6 Janos,

\footnotetext{
'According to Kohace, the Catmbalom is a Fallachinn inatrument. Undeniably thero b an element of truth in this theory inasmuch al our. Wallechin brethren aleo need the Crimbalom.

Of the many gates by which the Csimbalom could have entered Hungerg, one wes perhape a Wallechian (to-das Roumanian) port, the one lying nearest to Italy. for there, as we have remertred above, the Crimbelom wes widely ueed.
} 


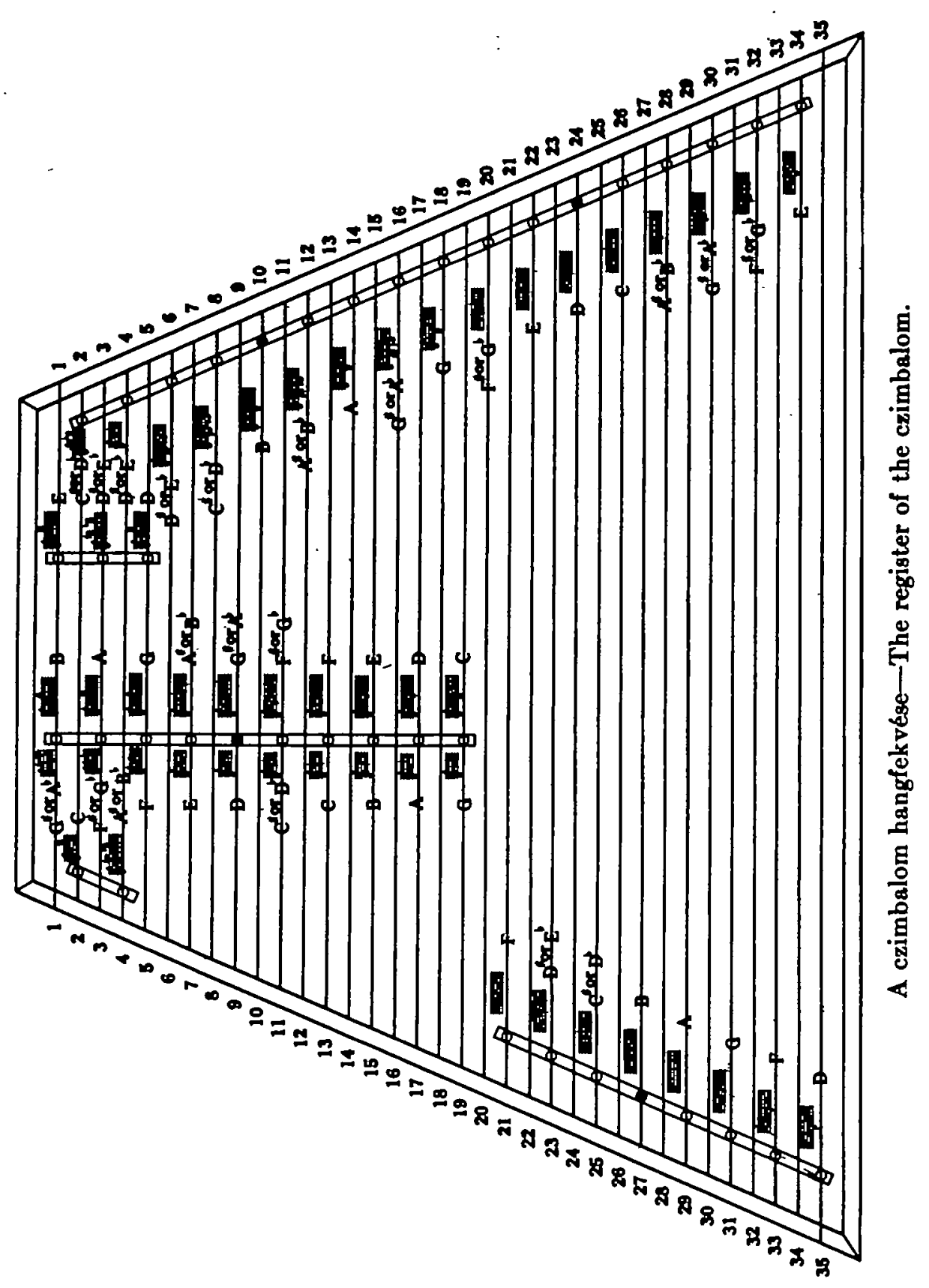


The Crimbalom, Hungary's National Instrument 597

called the "Tékozlo fio" is silent about the Crimbalom in the verses in which he praises the instruments used in his days. Yet we have seen that the instrument then was far from unknown, even though the Hungarian had not yet consecrated to it his greatest love as being the one instrument which so deeply speaks to his heart, which translates the melancholy of the deserts and which in every way best expresses his world of emotions. When, at the end of the eighteenth century, the hammer pianoforte had conquered its predecessors, the Hungarian accepted it but he felt at the same time that still in the realm of sentiment and tone-color no instrument so interpreted the melancholy or martial fierceness of his moods as did the Crimbalom: it has retained the place of favor in his heart as his national instrument.

\section{The Mrganamigm of the Cembazom.}

The notation for the Crimbalom is in both the treble and bass clefs. Its range is chromatic, from to with the exception of the two lowest notes-D-E-which are a whole tone apart.

Prom G to $\mathbf{E}$ each set of strings consists of four wire strings, graded to points of thickness and thinness necessary for producing the vibrations equivalent to certain tones. The bass, from F sharp down, have each three strings to each tone. The lowest string has but two. The strings are tuned by a key similar to that of a piano-tuner's.

The difficulty in tuning lies in the fact that by means of small bridges, permanently fastened at the sides, one string often gives two tones and in some cases, the subdivision of strings by yet smaller bridges, gives three.

Thus:

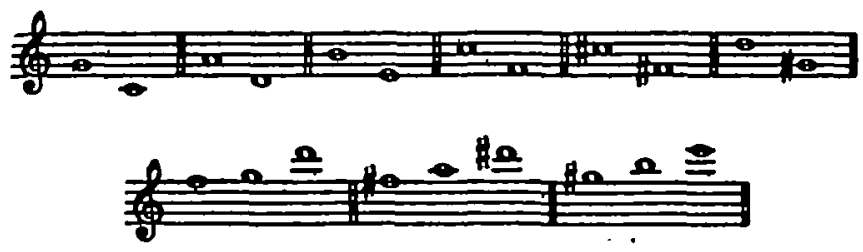

The loft hand is considered the first, the right hand the second. 
The small hammers are made of light wood yet sufficiently elastic to offer firm resistance to a blow. At the ends, which are curved upwards, they are filled in with cotton, tightly wound round. A small hollow is cut in the handle of the hammer. One holds the hammers between the second and third fingers, so that the thumb remains vertical and maintains its pressure on the middle finger.

There are two primary difficulties to be overcome in producing a beautiful and singing tone. One is, not to let the knockers rebound, for only a short and quick touch is necessary to set the strings in vibration; the other is to find exactly that part of the string where the tone is fullest. On the short strings, one would necessarily have to find this nearer the bridge than on the long strings. Immediately near the bridges the tone is hard and wooden; and again too far from the bridges the tone is hollow and colorless.

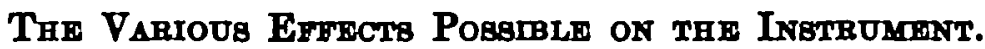

The Crimbalom is supplied with a single pedal, by means of which legato playing may be accomplished-one of the various effects possible on the instrument. The tone may otherwise be sustained by the repetitions of the hammer done with tremendous rapidity and evenness. Spiccato tones are produced by a short, sharp blow and with the pedal closed. Glissandos can be done as well as picking the strings with the finger-tips. Finally, a shrill and metallic tone can be produced by hitting the strings with the wooden end (the handle) of the hammer. The great advantage of the Crimbalom over the harp is in that it can ropeat notes, and in any degree of nuance desirable.

The length of the Crimbalom is approximately four and one half feot and its width about two and one half feet.

The Crimbalom was first used in an orchestra when on March 9, 1861, it was introduced in the Budapest National Opera House in Franz Erkel's Opera, "Bánk Bán." Mosonyi, writing in the music paper of the day, "Zenészeti Lapok" said:

The Composer has, in the second act, created a veritable orgy of sound, for here one may truly find everything. Artistic sincerity of expression, original and overwhelming musical ideas and tone-colours of rare power and effectiveness. The principal role was taken by the Crimbalom which, combined with the Viole d'Amour, the harp and the English horn, simply ravished the hearers and carried them to expressions of tumultuous applause. 
The Czimbalom, Hungary's National Instrument $\quad 598$

The seductive beauty of the tones of such a combination of instruments must have been voluptuously gorgeous indeed!

Up to this time, the instrument was incomplete in 80 far as there was no means of stopping the vibrations of the strings, once one had quitted them, and the blurring of one dissonance into another was far from agreeable to the ear. Furthermore, there was no standard of tuning. There was the so-called "Zsido" (Jew) way and the 8o-called Hungarian. According to the former, a great number of the tones and chromatics were entirely lacking; and according to the latter, the true intonation was almost impassible to establish firmly, because of the deficient way in which the bridges were placed.

Added to these limitations was another, equally important: the lack of any sort of method by which the instrument might be taught.

As no player of the instrument existed whom one might have considered an authority and as gypsies are not only ignorant of "music" but antagonistic to everything which demands order or logic, a beginner's primer was compiled by Schunda and Hiekisch and published by the former in Budapest, 1873-74. Subsequently a more complete method was compiled by Geza Allaga, also published by Schunda.

The first pedal-Crimbalom came into existence when in the year 1874 W. Josef Schunda, the Crimbalom manufacturer, added a pedal. The device is exceedingly simple and one is rather amused at the "pains" of the "inventor" and the glory he insists on having for "the years of devotion and endless research."

At each side of the instrument, in the middle of the resonance box, a small hole was bored, about the width of a thin pencil. Into each of these a long nail of brass was passed. The pedal was fastened, under the body, in the middle of the Crimbalom and with two boards, on hinges, acted on these brass pieces which raised the dampers on top of the strings. The weight of the felt-covered dampers pressed the nails back again.

Liszt incorporated the Cximbalom in his "A Magyarok Istene," his "Vihairndul6" (published in 1843 by Schlesinger in Berlin, as the "Seconde Marche Hongroise" for piano, but known as the "Ungarischer Sturmmarsch" for Orchestra with Czimbalom) and in his third orchestral Rhapsody (No. 6 for piano solo).

Friedrich Bodenstedt, known as the "Persian poet" "Mirza Schaffy" dedicated many of his fancies to the entrancing tones of the Czimbalom and, naturally, lesser poets were not slow to imitate him. 
In June 1890 a chair was created for the Cximbalom in the National Conservatory of Music at Budapest and Geza Allaga was chosen as its teacher. In 1897 the Royal Hungarian Academy of Music followed suit by appointing Kun Laszlo to the chair of Crimbalom instruction. It was under L6sal6 Kun that the writer at one time studied the Crimbalom in Budapest.

At present over ten thousand Crimbaloms are in use in Hungary alone, and they are also to be found in collections or in the possession of individuals in every country of the world.

It is to be earnestly hoped that the present-day composers will familiarize themselves with this truly beautiful instrument and will learn effectively to combine its lovely tone with other instruments which have for long been most undeservedly neglected. I refer to the viola d'amore, the low flute and the oboe d'amore. 